\title{
Botanic, Phytochemistry and Pharmacological Aspects of Phyllanthus Amarus Schum. \& Thonn. as Powerful Tools to Improve its Biotechnological Studies
}

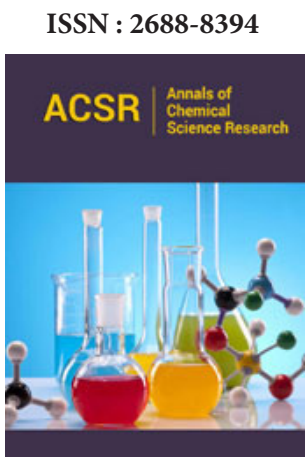

*Corresponding author: Maria Aparecida MM, Programa de Pós-Graduação em Biotecnologia, Universidade Potiguar Laureate International Universities, Campus Salgado Filho, Brazil,

E-mail: mammaciel@hotmail.com

Submission: March 28, 2019

Published: 眥April 22, 2019

Volume 1 - Issue 2

How to cite this article: Maria AM. Botanic, Phytochemistry and Pharmacological Aspects of Phyllanthus Amarus Schum. \& Thonn. as Powerful Tools to Improve its Biotechnological Studies. Ann Chem Sci Res. 1(2).ACSR.000510.2019. DOI: 10.31031/ACSR.2019.01.000510

Copyright@ Maria Aparecida MM, This article is distributed under the terms of the Creative Commons Attribution 4.0 International License, which permits unrestricted use and redistribution provided that the original author and source are credited.
Maria Aparecida M Maciel*, Gineide Conceição dos Anjos, Sthephanye Maurício Revoredo, Deborah de Melo Magalhães Padilha and Heryka Myrna Maia Ramalho

Post Graduate Program in Biotecnology, Potiguar University Laureate International Universities, Natal, Brazil

\begin{abstract}
Phyllanthus (Euphorbiaceae) is a native genus of the American continent representative medicinal plant with very high number of species (more than 1,000 ) located in tropical and subtropical countries. In Brazil, this genus is represented by over than 100 specimens, that are widely distributed in different environments. In fact, Phyllanthus is present in almost all Brazilian territories. The species of this genus are extremely used in folk traditional medicine. The species Phyllanthus amarus Schum. \& Thonn. and $P$. niruri $L$. have been frequent targets of ethnopharmacological work. However, in the beginning of this century botanic studies were intensified by using molecular markers for unambiguously identification of Phyllanthus species and to indicate the significant differences between the specimens of this genus. There are many differences between P. amarus and P. niruri, and the main of them were found to be in base, seed and stigma type. Systematic studies at molecular level have been assessed for acute authentication of plant specimen by using RAPD, ISSR, SCAR, AFLP, ITS, RFLP, ISSR-PCR and PCR-RFLP-ITS markers linked to a dominant gene. These methods have been assessed to the genus Phyllanthus with highly efficient results. With respect to phytocomponents of P. amarus herb, it is proved that the lignans Phyllanthin and hypophyllanthin are the main biomarkers. Focusing in one example phytochemical investigations were conducted with an unambiguous identified P. amarus collected from Brazil. Its ethanolic extract, revealed the presence of six bioactive lignans (phyllanthin, hypophyllanthin, isolintetralin, demethylenedioxyniranthin, 5-demethoxy-niranthin, niranthin) and one triterpene (2Z, 6Z, 10Z, 14E, 18E, 22E-farnesilfarnesol). This rich lignan extract was used in nanoemulsion formulations, an efficient therapeutic medicine to be applied in the health care. Other polar extracts of $P$. amarus have been encapsulated by using bio-nanotechnologies and are presented in this review. Technological innovations and recent progress in the multiple aspects of Phyllanthus's plant development was reviewed. Today's current state of Phyllanthus amarus Schum. \& Thonn. is supported by its scientific findings, which has many applications, of which mainly focusing in the biotechnology field to face the new challenges for this lead medicinal plant.
\end{abstract}

Keywords: Phyllanthus; Phyllanthus amarus Schum. \& Thonn. Morphology; Herbal Authentication; Phytochemical and Pharmacological properties; Biotechnological studies

\section{Introduction}

Phyllanthus (Euphorbiaceae) is a native genus largely used as antipyretic, antiviral, antidiarrheal, antispasmodic, antinociceptive, anti-inflammatory, antioxidant, antitumoral, antigenotoxic, antimutagenic, hepatoprotection, hypoglycemic, hypotensive, diuretic, antidiabetic, bactericide. It was also efficient for fighting jaundice, hepadnaviral DNA polymerase, AIDS and kidney disorders [1-10]. Phyllanthus amarus Schum. \& Thonn. and Phyllanthus niruri L. have been frequent targets of ethnopharmacological work all over the world, mainly in Brazil, U.S.A, Malaysia, Cuba, Peru, Caribbean, China, Nigeria, Africa and India [8-10]. Despite the large number of literature registers, these species have been published as being synonymous because of their morphological similarities. Phyllanthus species had been botanic approached by using several methodologies in the extended period of 2003 to 2011. Silva et al. [11], pointed out significant differences between P. amarus and P. niruri, collected from Pernambuco state of Brazil. The main differences are indicated on the base, seed and stigma type [11]. 
Because of the folk medicinal importance of P. amarus as well as its previous mistakable identification, some scientific aspects about this plant such as botanic, ethnobotanic, phytochemical, pharmacological and biotechnological studies will be highlighted in this work. P. amarus in its extremely dynamic field is notorious. The folk and scientific medicinal history of this herb thoughtfully integrated into the nanotechnological considerations in order to get new therapeutic efficiencies. Physicochemical characteristics of nanoparticle suspensions, particle size distribution, morphology, surface charge, drug release profiles and many others are very important pre-requisites. These pre-requisites can produce highperformance materials with specific functionality that lead in the success of any dosage form development.

\section{Materials and Methods}

The literature survey for this review was obtained from different scientific sources such as Web of Science, PubMed, Google Scholar and the Brazilian virtual library CAPES Periodic Portal which includes Science Direct and other scientific resources.

\section{Result and Discussion}

Specimens of the genus Phyllanthus are widely used as traditional medicines and consist of more than 1,000 species found in tropical and subtropical countries of the world. Phyllanthus amarus Schum. \& Thonn. is well known since ancient times (about 3000 years) [5,8,9]. This plant is a small herb $(30 \mathrm{~cm}-60 \mathrm{~cm})$ commonly called stone breaker, wind breaker, carry me seed, and many other folk designations. The word Phyllanthus means leaf and flower, mainly because of its appearance, where flower, fruit and leaf appear to be fused [12]. The taxonomy of the genus Phyllanthus is the following: Kingdom: Plantae, Division: Angiospermae, Class: Dicotyledoneae, Order: Tubiflorae, Family: Euphorbiaceae, Genus: Phyllanthus, and Species: amarus $[8,9,12]$. The general characters of this genus are i) Habit: herbs or shrubs, ii) Leaves: small, alternate and distichous, iii) Branchlets: resembling pinnate leaves with stipules narrow, iv) Flowers: very small without petals, monoecious, in axillary clusters or solitary, bracteates, disk in male flowers with small glands and annular in female flowers with large glands, v) Lobes: 5-6 imbricated, vi) Stamens: three of which more or less free or the filaments combined in a column, the others oblong, didynamous, dehiscing vertically or transversely, vii) Ovary: three of celled, styles 3, free or connate at base, viii) Fruit: A capsule with crustaceous or thin 2-valved cocci, and ix) Seeds: trigonal, rounded at back $[8,9,12]$. With respect to Phyllanthus amarus Schum. \& Thonn. it shows i) stem angular with numerous distichous, ii) slender leave bearing branchlets, distichous subsessile with elliptic-oblong obtuse, rounded base leaves, iii) flowers are axillary and yellowish, whitish or greenish, and males flowers are in group of 1-3 whereas females are solitary, iv) fruits are depressed-globose like smooth capsules present underneath the branches, v) seeds are triangular, pale brown, $1 \mathrm{~mm}$ long with 5-6 longitudinal parallel ribs on the back, and vi) capsules on stalks are $1 \mathrm{~mm}-2 \mathrm{~mm}$ long, round, smooth, $2 \mathrm{~mm}$ wide six seeds. The whole herb shows explosive seed capsules that propel the seeds some distance from the plant $[8,9,12]$.
Focusing on the genetic diversity of Phyllanthus species and its morphological similarities, Sarin et al. [6] described the importance of this plant genus identification along with pharmacological and phytochemical studies, as well as appropriate protocols for correct identification of species [6]. Webster [13] notified that Phyllanthus niruri $L$. species had never been confirmed outside the American continent. So, it was clarified that Phyllanthus niruri is an American species and not at all found in India [13]. After that, Mitra and Jain [14] showed all species identified as $P$. niruri are $P$ amarus, $P$. debilis or $P$. fraternus [14]. In this context, the botanic concept of Phyllanthus species was approached by several authors along all the years from 2003 to 2011 [11,14-29]. The genetic diversity analysis had been performed using random amplified polymorphic DNA (RAPD) and inter-simple sequence repeat (ISSR) markers as well as average polymorphism. Species collected from different geographical locations in India, showed high intrapopulation variation. The phenomena had been attributed to the crosspollination mechanisms in in populations and also because they grow as weeds without much anthropogenic intervention. Isozymes also have been used to assess the genetic variability in south Indian populations of P. amarus to identify superior genotypes aiming to improve drug quality formulation strategies for in situ conservation and also to sustainable uses [17]. Silva et al. [11], showed significant differences between Phyllanthus amarus Schum. \& Thonn. and Phyllanthus niruri L. by applying a traditional morphologic botanic approach. The results showed that $P$. niruri $L$. presents asymmetric base of lamina, capitated stigma and seeds with many verrucula in longitudinal lines. Meanwhile, Phyllanthus amarus Schum. \& Thonn. has asymmetric base of lamina, but the stigma is not capitated, and the seeds are striated [11]. Nowadays, it is clear that $P$. niruri and $P$. amarus are two different species and the evaluation of the Phyllanthus niruri L., Phyllanthus amarus Schum. \& Thonn. as well as Phyllanthus sellowianus Mull. Arg. is a difficult task and does not bring satisfactory results. Indeed, P. amarus and $P$. sellowianus present the same appearance as well as similarities on phytochemical and medicinal contents when compared with $P$. niruri [11]. The analytical techniques, HPTLC (high performance thin layer chromatography) and HPLC (high-performance liquid chromatography), of many samples applied simultaneously by using the same plate also reduces time and cost analysis. Khan et al. [34] based on morphological aspects assessed 19 populations of this species collected from different geographical regions of India. It was found that all of them were different and they had different phytochemical markers. This assessment was conducted using HPTLC technique and showed that phytochemical diversity was found more in leaves followed by seeds, stem and roots from one geographical region to another one [34]. Nasrulloh et al. [35] proved that HPLC fingerprint is a precise and accurate method for the identification and authentication of Phyllanthus species. They found that the highest amount of the biomarkers phyllanthin and hypophyllanthin was in P. niruri compared to P. debilis and $P$. urinaria. Fingerprint chromatogram of the three Phyllanthus species showed distinct profiles. These profiles may be used to identify and authenticate each Phyllanthus species [35]. Additionally, authenticity analysis of Phyllanthus amarus were also performed 
using DNA barcoding coupled with HRM analysis as quality control in the production of phytotherapeutics [36]. Nowadays, molecular markers such as RAPD, ISSR, ISSR-PCR (inter-simple sequence repeat-polymerase chain reaction), SCAR (sequence characterized amplified regions), AFLP (amplified fragment length polymorphism), ITS (internal transcribed spacers), and the codominant marker RFLP (restriction fragment length polymorphism) as well as PCR-RFLP-ITS approach were significantly applied to Phyllanthus specimens for its unambiguous botanic identification [17-29]. Taking in account the pharmacological importance of P. amarus and Phyllanthus niruri, they are traditionally taken as an infusion of the whole plant (in a glass of boiling water). It has a large therapeutic use in popular medicine for treating kidneys (fighting cystitis, kidney gravel and expelling stones), viral hepatitis, epilepsy, flu (intermittent fevers), bronchial infection, asthma, tuberculosis, constipation, diarrhoea, cramps, jaundice, furuncle, hypertension, intestinal and genitourinary (vaginitis) infections, gonorrhoea, menorrhagia syphilis, and malaria. The infusion is also taken as a muscular relaxing, and to fight diabetes and high levels of cholesterol. These species also have been cited as astringent, stomachic, diuretic, febrifuge and antiseptic. They are also used as antiulcerogenic, antitumoral, hypoglycemic, hypotensive, antiinflammatory, analgesic, antioxidant, antibacterial, antimalarial and antiviral (including AIDS), antimutagenic, antispasmodic, immunosuppressive, ophthalmopathy, scabies, ant plasmodial, cardioprotective and wounds [5,8-10,37-66].

More than 510 compounds have been isolated from Phyllanthus species from which lignans, triterpenoids, flavonoids, and tannins. Corilagin, geraniin, and gallic acid are three most prevalent compounds in this genus. The pharmacological researches mainly focus on phyllanthin, niranthin, and geraniin. Since lignins and tannins compounds exhibit various activities, they are considered the most biological active compounds of this genus. In general, the phytocompounds isolated from organic solvent extracts of $P$. amarus holds the largest number of phytochemical studies of this genus followed by P. niruri, P. urinaria, P. emblica, P. flexuosus, and P. sellowianus [5,67]. Concerning to Phyllanthus amarus, numerous constituents have been reported such as alkaloids, tannins, flavonoids, lignins, polyphenolic compounds, and tetracyclic triterpenoids. Those phytocompound classes establish the therapeutic importance of this plant. Focusing on tannin there are phyllanthusiin A, B, C, and D, furosin, elaeocarpusin, amariinic acid, repandusinic acid A, geraniin acid B, amarulone, melatonin, isocorilagin, and 1,6-digalloylglucopyranose. Several bioactive alkaloids are described for this herb such as securinol, allo-securine, securinine, nor-securinine, dihydrosecurinine, tetrahydrosecurinine, epibubbialine, iso-bubaline, phenazine and its semi-derivatives compounds. The flavonoid compounds are quercetin, quercetin-3-0-glucopyranoside, Gallo catechin, astragalin, kaempferol, and rutin. Benzenoid compounds are gallic acid and corrillagin. The constituents of the volatile oil are phytol and linalool. Amarosterol A and B are present in P. amarus as sterols phytocompounds. The isolated triterpenoids are $2 \mathrm{Z}, 6 \mathrm{Z}, 10 \mathrm{Z}, 14 \mathrm{E}$, 18E, 22E-farnesilfarnesol, ursolic and oleanolic acids, phyllanthenol, phyllanthenone, and lupeol $[6,37,68]$. Comparative inorganic profile of leaf-derived in vitro calli and in vivo leaf samples of Phyllanthus amarus was performed by using ED-XRF spectrometry method [69]. According to Calixto et al [3], Phyllanthus amarus, Phyllanthus fratenus, and Phyllanthus maderaspatensis have significantly different phytochemical characteristics. The findings of this study showed that only P. amarus contain phyllanthin and hypophyllanthin which were correlated with the hepatoprotective activity of this species [3]. Meanwhile, by using HPTLC methodology, Tripathi et al. [70], proved that phyllanthin and hypophyllanthin are present in both herbs $P$. fratenus and P. amarus, but with different amounts [70]. A comparative phytocomposition studies among Phyllanthus amarus, Phyllanthus maderaspatensis, Phyllanthus virgatus and Phyllanthus urinaria showed that phyllanthin, hypophyllanthin, niranthin, virgatusin, nirtetralin, and a lactone compound, so called called heliobupthalmin, present in all studied herbs [71] which support the previous results. On the other hand, these results have been contested by other authors who did not find phyllanthin and/or hypophyllanthin in the Phyllanthus maderaspatensis and Phyllanthus urinaria [72,73].

In a previous work, a phytomedicinal study of Phyllanthus amarus Schum. \&Thonn. reported that this plant was unambiguously identified, and then was evaluated for its gastrointestinal activity. A phytochemical approach applied to the methanol extract of the whole plant in order to isolate lignans. By using NMR technique, the presence of phyllanthin and hypophyllanthin was confirmed along with another 4 bioactive lignans, isolintetralin (2,3-demethoxyseco-isolintetralin diacetate), demethylenedioxy-niranthin, 5-demethoxy-niranthin, niranthin, and one triterpene $(2 \mathrm{Z}, 6 \mathrm{Z}, 10 \mathrm{Z}$, 14E, 18E, 22E-farnesil farnesol) (Figure 1), [68]. The methanolic extract was carried out to evaluate in vivo gastrointestinal transit influence of Phyllanthus amarus, and the main pharmacological activity was correlated to lignans. The oral administration of mice $(0.1,0.3$ or $1 \mathrm{~g} / \mathrm{kg})$ with the methanolic extract caused a significant dose-related reduction of charcoal intestinal transit $(6.8 \pm 0.4 \%$, $35.6 \pm 2.9 \%$ and $58.5 \pm 6.2 \%$ ), respectively, compared to the control vehicle group (IC50 $=631 \mathrm{mg} / \mathrm{kg}$ ). Atropine used as positive control reduced this parameter by $80 \%$. These pharmacological results justify the traditional uses of Phyllanthus amarus Schum. \& Thonn. against gastrointestinal disorders [37].

In general, studies dealing with i) utilization and conservation of plant, ii) genetic authentication, and iii) genetic diversity evaluations such as phylogenetic and characterization of germplasm are strongly important for improvement of herb's large-scale production. In fact, for the purpose of metabolic engineering or plant breeding, scientists are widely using genetic transformation approaches as a powerful tool to improve signal transduction, genome organization, pathogenesis process, or even to modify the secondary metabolic content of human useful herbs. With respect to Phyllanthus genera, the total number of genetic diversity investigations are greatly reduced compared to the huge amount of phytochemistry, pharmacological and pharmacogenetic studies. An accurate authentication of Phyllanthus plant specimens molecular level biotechnology methodologies have been evaluated 
applying some markers linked to a dominant gene. These studies were conducted by applying genomic DNA through different procedures. In fact, several authors have been successfully assessing this biomarker on the genetic variability of $P$. amarus in order to identify superior genotypes for improving drug quality as well as for formulation strategies to be used in situ conservation and sustainable utilization [17-29].

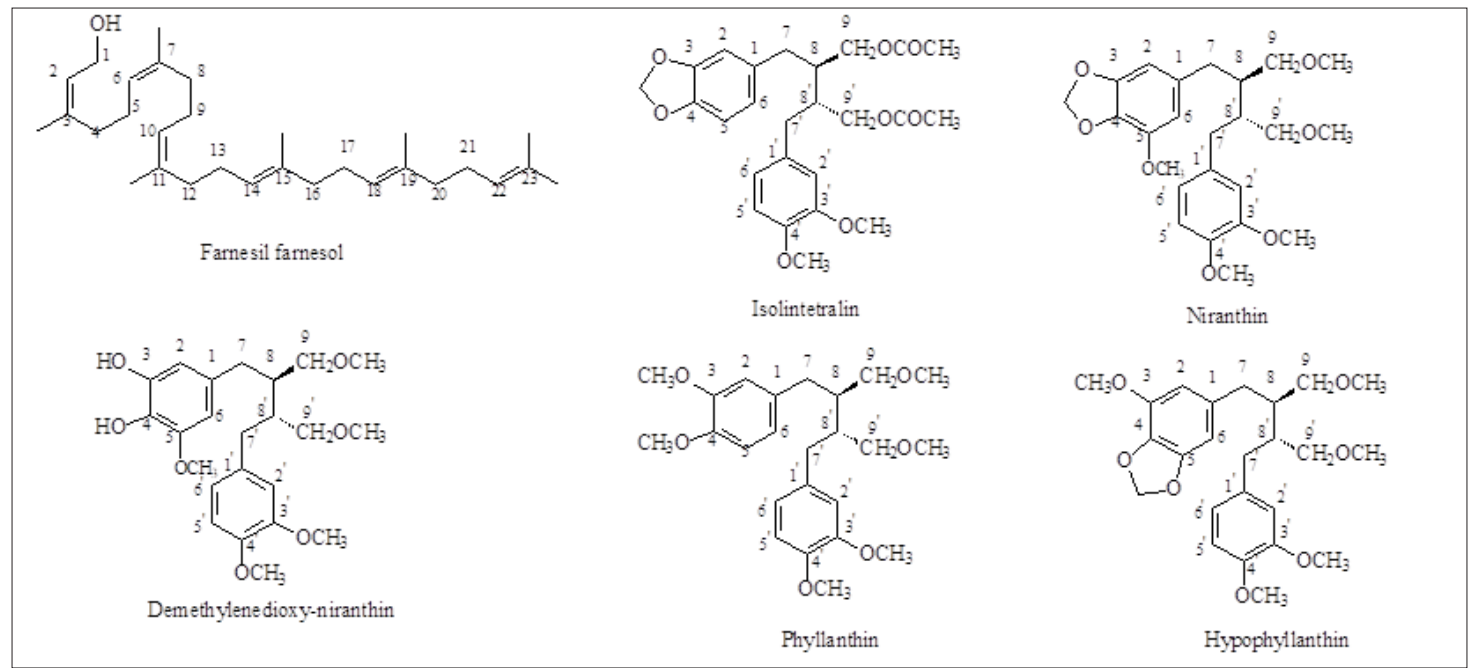

Figure 1: Chemical structures of some Phyllanthus amarus bioactive constituents.

Reinforcing the importance of these findings, a study was done by Inglis et al. [27] who assessed plants of the genus Phyllanthus, that have been used in Brazilian folk medicine to treat kidney stones and other ailments, such as $P$. amarus, $P$. urinaria, $P$. niruri, and $P$. tenellus. This study showed that only $P$. niruri could be effective in a clinical setting. The nuclear ribosomal internal transcribed spacer (ITS1-5.8S rRNA-ITS2), internal transcribed spacer 2, chloroplasts rbcL, matK, psbA-trnH, trnL, and trnL-trnF were screened for their potential as DNA barcodes for the identification of 48 Phyllanthus taxa in Brazilian medicinal plant germplasm banks and in "living pharmacies". The markers were also tested for their ability to validate four Brazilian commercial herbal teas labelled as quebra-pedra (stone-breaker) by using the criterion of high clade posterior probability in Bayesian phylogenetic analysis, such as the internal transcribed spacer, internal transcribed spacer 2, and chloroplast matK, psbA-trnH, trnL, and trnL-trnF markers all reliably. The results obtained from these commercial herbal teas showed four different Phyllanthus species. Internal transcribed spacer and matK showed that the genus is well represented for these markers in the Gen bank database. Conclusively, in the case of rbcL, posterior probability for some clades was low, P. amarus and $P$. tenellus formed monophyletic groups, while $P$. niruri and $P$. urinaria accessions could not be reliably distinguished with this marker. Packaged dried quebra-pedra herb from three Brazilian commercial suppliers comprised $P$. tenellus, but one sample was also found to be mixed with alfalfa (Medicago sativa). In addition, a herb marketed as quebra-pedra from a fourth supplier was found to be composed of a mixture of P. niruri and Desmodium barbatum [27].

Senapati et al. [28] attempts to identify species by applying diagnostic markers for some Phyllanthus species using the inter simple sequence repeat-polymerase chain reaction (ISSR-PCR) fingerprinting method as well as PCR amplification using seven ISSR primers. The findings showed that seventeen speciesdiagnostic markers were identified for seven species (P. acidus, $P$. emblica, $P$. fraternus, $P$. urinaria, $P$. rotundifolius, $P$. amarus, and $P$. angustifolius) while no marker was detected for $P$. reticulatus, $P$. nivosus, and $P$. virgulatus. PCR/ISSR resulted in significant polymorphism among the populations from different species. According to the results $P$. angustifolius and P. urinaria showed monomorphic frequency ranging from $63.88 \%$ (maximum value) to $20.64 \%$ (minimum value). A maximum of six species-diagnostic markers were identified for $P$. acidus and a minimum of only one of $755 \mathrm{bp}$ was available for $P$. amarus. Among the seventeen markers, nine were present in all individuals of species. Conclusively, the species-specific differences in fragment numbers and sizes could be used as diagnostic markers to quickly distinguee the Phyllanthus species [28]. In earlier studies Marimuthu and Antonisamy [29] compared the phytochemical constituents of Phyllanthus amarus by using molecular markers (isozyme), in which calli production and organogenesis were applied to P. amarus sample. In this field, there are few available reports for phytochemical analysis in an in vitro approach devoted to derived cultures, emphasizing on biochemical and phytochemical comparative studies focusing on somaclonal variation under isoperoxidase conditions. The findings showed equal appearance of bands between the mother plant and nodal derived plant (directly regenerated ones) proved that the isoenzyme system successfully reveal the morphological and biochemical variation of the plant and also reveal the somaclonal variation very clearly by the banding positions occupied by the calli mediated plants in the superoxidase gel system. The phytochemical evaluation confirmed the presence of other alkaloids, saponins, tannins as well as other compounds from calli and calli mediated 
shoots and roots [29].

Concluding this part or this review it is notorious that the limitations of chemical and morphological approaches for plant authentication, had generated the need for newer methods in quality control of botanicals of which assess of genetic variation protocols are the most relevant point. In general, the desirable properties of molecular markers must include the following basic rules: i) assays should be easy, rapid and available, ii) reproducible and highly polymorphic, iii) co-dominant inheritance and recurrent occurrence in genome, iv) selectively neutral to environmental conditions, and v) valuable advantages and restrictions should be highlighted in the selection of the ideal approach for a large scale production. Concerning to Phyllanthus specimens, using different molecular marker-based it was possible to define significant variations among them. The genomic DNA technique proved to be both very reproducible and cost effective [17-29]. The advances in biotechnology studies on genetic diversity such as RAPD, ISSR, SCAR, AFLP, ITS, RFLP, ISSR-PCR and PCR-RFLPITS markers linked to a dominant gene along with other ones DNA amplification fingerprinting (DAF), arbitrarily primed polymerase chain reaction (APPCR), simple sequence repeats (SSRs), sequence characterized amplified regions (SCARs), cleaved amplified polymorphic sequence (CAPS), expressed sequence tags (ESTs), single nucleotide polymorphisms (SNPs) and sequence tagged sites (STSs). In a general context, for genotypes close related, genetic variation present in different sources could interfere or combine with the more or less polymorphic ability. So, the analysis of variability could require more than one DNA-based technique. So, best-suited molecular assay for fingerprinting and assessing genetic relationship among genotypes shows their own advantages and limitations. In this sense, among the available biotechnological analysis of plant genetic diversity and DNA fingerprinting still not available an ideal technique that had yet fulfil all requirements needed by plant researchers [30-33].

Originally, the growth of the biotechnology industries is related to the principles of fermentation process that boosted the very large production of antibiotics, enzymes, amino acids and improved the application of living biological materials such as microorganisms to create new relevant technologies process. Currently, the high biotech engineering is widely associated to the wealth genetic researches which generates new products as well as improvement in terms of plant biology, cell biology, molecular biology, protein, enzymes and vaccines engineering, biochemistry and its nanotechnologies. Nowadays, there are over then 10,000 pharmaceutical companies producing thousands of pharmaceutical products. The nanotechnology molecular construction is a science related to the manipulation of the substances at molecular level aiming at to create new materials. Nanomaterials with sizes rage from $0.1 \mathrm{~nm}$ to $100 \mathrm{~nm}$, are similar to many biomacromolecules and organelles. When the size of material decreases to nanometer level, the small size effect surface along with quantum size effect and quantum tunnelling effect will play significant roles, and consequently enable nanomaterials with new properties, such as the increasing hardness, super paramagnetic, strong surface adsorption capacity, chemical reactivity and quantum properties. In order to infer the feasibility of nanoscience on the therapeutic efficacies of $P$. amarus, actually few researches are devoted to achieving bioavailability enhances from this very important medicinal pant. The efficiency of the poor soluble ethanol extract (EtOH) of $P$. amarus loaded in a nanoemulsion system was $89 \%$ at optimum concentration $(2: 18 \mathrm{mg} / \mathrm{mL}$ of EtOH extratct: olive oil). This nanocarrier system containing dispersion of EtOH extract (in an aqueous sodium alginate medium in the presence of olive oil and Tween $80 \AA$ as the surfactant solution) was prepared by emulsion-coacervation method caused, in which alginate shell was solidified by cross-linking with analytical grade $\mathrm{CaCl}_{2}$ and then, the solvent was removed by evaporation under pressure. Variation in proportion of P. amarus EtOH extract and olive oil afforded nanocapsules ( $\mathrm{pH} 7$ ) obtained as dispersion in aqueous phase. In this nanoformulation, the phytoconstituents of $P$ amarus remain stable and the oral dose $(20 \mathrm{mg} / \mathrm{kg}$ body wt) showed a better hepatoprotective effect when compared to the unload P. amarus EtOH extract, administered in higher concentration $(100 \mathrm{mg} / \mathrm{kg}$ body wt). Indeed, this nanoemulsion formulation proved to be both efficient and safe and no toxicity was evidenced even for the repeated oral dose [74].

So, this finding, if applied as a commercial medicine for human treatment, could reduce the dosage and period of treatment enlarging the safety use of $P$. amarus. Silver nanoparticles $(15.7 \mathrm{~nm}-29.78 \mathrm{~nm})$ were synthesized based on the aqueous extract of $P$. amarus, and then were explored as a potent source of nanomedicine against multidrug resistant microbes (MDR). The zone of inhibition increased with increase in the concentration of silver nanoparticles $(12.5 \mu \mathrm{g} / \mathrm{mL}$ to $100 \mu \mathrm{g} / \mathrm{mL})$ and the MIC was observed in the range of $6.25 \mu \mathrm{g} / \mathrm{mL}$ to $12.5 \mu \mathrm{g} / \mathrm{mL}$ and are comparable to the standard antibiotics. So, the antibacterial effect of this P. amarus. bionanoformulation against MDR strains gives insights to be applied in the health care system [75]. Acharyulu et al [76] performed a green synthesis of $\mathrm{Cu} 0$ nanoparticles with average particle size of $20 \mathrm{~nm}$, developed in the presence of $P$. amarus leaf extract. The antibacterial activity of these nanoparticles was tested against various multidrug resistance bacteria such as Grampositive (B. subtilis and S. aureus) and Gram-negative (E. coli and P. aeruginosa) [76].

Mishra et al. [77] compared the hepatoprotective effects of $P$. amarus the ethanolic extract (PAE) with its nanoparticles (PAN) formulations on paracetamol induced acute liver toxicity in Sprague-Dawley rats. An oral dose of PAE at $125 \mathrm{mg} \mathrm{kg}^{-1}$ and $250 \mathrm{mg}$ $\mathrm{kg}^{-1}$ and PAN at $25 \mathrm{mg} \mathrm{kg}^{-1}$ and $50 \mathrm{mg} \mathrm{kg}^{-1}$ showed a significant hepatoprotective effect relatively to the same extent $(\mathrm{P}<0.001)$ by reducing levels of aspartate aminotransferase, alkaline phosphatase and bile salts. These biochemical assessments were supported by rat hepatic biopsy examinations. Moreover, the results also indicated that the hepatoprotective effect of $50 \mathrm{mg} \mathrm{kg}^{-1}$ PAN was effectively better than $125 \mathrm{mg} \mathrm{kg}^{-1} \mathrm{PAE}(\mathrm{P}<0.001)$, and an oral dose of PAN that is five times less than PAE could exhibit similar levels of outcomes [77]. 
In conclusion, it was found that an oral dose of PANs that is five times less than the oral dose of PAE could exhibit a similar hepatoprotective effect [77]. In a very recent studyAjitha et al. [78] reinforce the antimicrobial activity of $P$. amarus leaf extract nanocarrier on a bio-synthesized AgNPs silver nanoparticle system approached through an easy, rapid and eco-friendly pathway. The antimicrobial and catalytic activities of the were carried out and the results indicated that the concentration of the Ag precursor and the volume of the leaf extract played key roles in the formation of the flower-shaped AgNPs. Morphology study confirms the shape of the obtained bio-AgNPs as flower like structure. This study also showed the presence of clear capping layers surrounding and apparently interacting with the AgNPs nanoparticles. Moreover, it was observed interaction to involve bio-organic capping agents in the leaf extract. Additionally, this AgNPs bioanalyses showed to be an excellent microbial active agent against the selected pathogens and enhanced catalyst of the reduction of rhodamine B [78].

An earlier environmentally friendly approach was employed to synthesize silver nanoparticles and the results showed that biomolecules found in plants induce the reduction of $\mathrm{Ag}^{+}$ions from silver nitrate to silver nanoparticles (AgNPs) and also produced good antimicrobial activity against common pathogens. In addition, antioxidant activities were performed by using DPPH antioxidant assay and hydrogen peroxide assay. Plants during glycolysis produce a large amount of $\mathrm{H}^{+}$ions along with NAD which acts as a strong reducing agent; this seems to be responsible for the formation of AgNPs [79]. Some et al. [80] reviewed the huge importance of modulating metals into solid nanoparticles (SNPs) which offer new scientific and industrial applications, including biomedical products based on P. amarus. Pointing out some advantages of AgNPs, they have been used as i) safe preservatives due to non-penetrating property to human skin, ii) in agriculture control an important crop pest and combat several herb diseases, iii) in chemical industry it preserves the environment acting against pesticide contamination by mineralization, iv) in biomedicine acts as antiviral, anti-inflammatory, anticancer, and antimicrobial ( $B$. subtilis, S. aureus, P. aeruginosa, P. pneumonia, and S. Flexneri) [80].

Other contribution in the development of bio-nanotechnologies of Phyllanthus amarus, consist in a target nanoemulsion system performed with low concentrations $(2.0 \mathrm{mg}$ and $5.0 \mathrm{mg}$ ) of a hydroalcoholic extract (HAE-PA) of P. amarus. This system was applied for in vitro evaluation on the culture of ovarian follicles. The efficacy of the HAE-PA extract loaded into a biocompatible nanoemulsion system (NE-PA) was evaluated in order to investigate the cellular viability in the follicular development of pig ovarian follicles. The diameters of the analyzed pig ovarian follicles range from $150 \mu \mathrm{m}$ to $600 \mu \mathrm{m}$ which were cultured for 4 days into a modified $\alpha$-MEM $\left(\alpha-\mathrm{MEM}^{+}\right)$as cultured control as well as in the presence of NE-PA. The modified $\alpha$-MEM culture of follicular treatment was carried out with the individually follicles incubated in $100 \mu \mathrm{L}$ drops under mineral oil. In the NE-PA treatment of follicular culture, the tested follicles were incubated in $200 \mu \mathrm{L}$ drops in the absence of mineral oil. The parameters evaluated in this experiment were the follicular viability rate through vital dyes (ethidium homodimer and calcein) and follicular diameter. In the in vitro culture of ovarian follicles, at least 30 follicles per group were evaluated and there was no statistical difference between the control group not cultivated and the cultured control one by using the NE-PA natural bioproduct. Viability data were compared using Chi-square test, the follicular diameters data were submitted to ANOVA, and treatments were compared using Student-NewmanKeuls (SNK) test. The antioxidant activity of the SN-PA formulation was evidenced by using sequestration of hydroxyl radicals and ion chelation tests (iron and copper).

In conclusion, the tested extract plant loaded at lower concentrations in the non-toxic and nutritive NE-PA formulation, which applied in follicular in vitro culture of pig ovarian follicles, for a short time, does not require feasibility to damage these follicles [81]. Focusing on scientific and technological advances in the interfaces between eco-friendly chemical products, it is well known that the corrosive materials is one of the main problems facing industrial process that causes environmental pollution and extreme financial losses. To examine the corrosion inhibition of $P$. amarus as an eco-friendly chemical product, the ethanolic extract of $P$. amarus was put in a microemulsion system (MES-PA) with saponified coconut oil as surfactant and its corrosion inhibition efficiency for AISI 1020 carbon steel was studied in 3.5wt.\% $\mathrm{NaCl}$ solution by weight loss measurements and potentiodynamic polarization technique. The MES-PA biofriendly formulation showed solubility improvement of the poorly water-soluble $P$. amarus extract with low surfactant concentrations. The results showed that MES-PA reached maximum inhibition efficiency of $94.8 \%$ at $50 \mathrm{ppm}$. The adsorption mechanism was shown the best fit with the Langmuir isotherm [82]. Finally, we conclude this paper by highlighting the potential of nanoscience and nanotechnology in the development of herbs ahead to arrive at high-performance and specifically functional materials of which nanomaterials-based drug delivery platforms allow rapid formulation development, among other advantages. In this context, P. amarus comes up with excellent perspectives of evolutionary scientific and technological applications.

\section{Conclusion}

This review attempted to present an overview of the existing studies on botanic, pharmacognostics, and phytochemical studies developed with Phyllanthus amarus Schum. \& Thonn. Brings strong highlights on Phyllanthus genetic diversity species and phylogenetic relatedness and also drew attention towards plant conservation strategies as well as new scientific approaches. These subjects are very important to underlined because there are no major research discussions on the unambiguous botanic identification of Phyllanthus specimens before undergoing on new scientific evaluations. Indeed, the last 20 years over then 1,000 articles were published with $P$. amarus and P. niruri herbs generally indiscriminately concerning to their botanic differences and focusing in the unambiguously specimen identification. In the other hand, despite of the huge previously scientific reports of $P$. amarus, still demand new pharmacological evaluations before 
commercialization in pharma industry. Hence, modern scientific protocols were reviewed focusing mainly on Phyllanthus amarus which is worldwide used in the traditional medicine cares and also as dietary adjuncts for the treatment of numerous physiological disorders including hepatic disorders. As a limiting factor due to the poor water solubility of P. amarus its major constituents such as lignans and flavonoids, shows poor absorption upon oral administration. Considering this limitation and also the significant properties of $P$. amarus the last part of this review was devoted to the description of nanoparticles formulations in order to overcome the poorly water solubility and to improve its bioavailability, and furthermore to decrease treatment dosage. In addition to that, it is well known that nanoencapsulation protocols prolong release of bio-compounds, protect them from degradation, decrease toxic or adverse side effects, offers appropriate forms for all routs of administration, offers systems for combined therapy, and reduce modern formulations development costs. This revision highlights Phyllanthus amarus as an emergent herb in the nanoscience field. Finally, this review may be a useful reference for future exploitation of new nanoparticulate systems for use of Phyllanthus species in biomedical applications.

\section{References}

1. Ogata T, Higuchi H, Mochida S, Matsumoto H, Kato A, et al. (1992) HIV-1 reverse transcriptase inhibitor from phyllanthus niruri. AIDS Res Hum Retroviruses 8(11): 1937-1944.

2. Unander DW, Webster GL, Blumberg BS (1995) Usage and bioassays in Phyllanthus (Euphorbiaceae): iv. clustering of antiviral uses and other effects. J Ethnopharmacol 45(1): 1-18.

3. Calixto JB, Santos AR, Cechinel Filho V, Yunes RA (1998) A review of the plants of the genus Phyllanthus: their chemistry, pharmacology, and therapeutic potential. Med Res Rev 18(4): 225-258.

4. Santos ARS, De Campos ROP, Miguel OG, Filho VC, Siani AC et al. (2000) Antinociceptive properties of extracts of new species of plants of the genus Phyllanthus (Euphorbiaceae). J Ethnopharmacol72(1-2): 229-238.

5. Patel JR, Tripathi P, Sharma V, Chauhan NS, Dixit VK (2011) Phyllanthus amarus: ethnomedicinal uses, phytochemistry and pharmacology: a review. J Ethnopharmacol 138(2): 286-313.

6. Sarin B, Verma N, Martín JP, Mohanty A (2014) An overview of important ethnomedicinal herbs of Phyllanthus species: present status and future prospects. The Scientific World Journal.

7. Mao X, Wu LF, Guo HL, Chen WJ, Cui YP et al. (2016) The genus Phyllanthus: an ethnopharmacological, phytochemical, and pharmacological review. Evid Based Complement Alternat Med.

8. Devi S, Rashid R, Kumar M (2017) Phytochemistry and pharmacological properties of Phyllanthus amarus schum. a review. The Pharma Innovation Journal 6(12): 169-172.

9. Meena J, Sharma RA, Rolania R (2018) A review on phytochemical and pharmacological properties of Phyllanthus amarus Schum. and Thonn. International Journal of Pharmaceutical Sciences and Research 4(9): 1377-1386.

10. Narendra K, Swathi J, Sowjanya KM, Satya K (2012) Phyllanthus niruri: a review on its ethno botanical, phytochemical, and pharmacological profile 5(9): 4681-4691.

11. Silva MJ, Sales MF (2004) 0 gênero Phyllanthus L. (Phyllantheae - Euphorbiaceae Juss.) no bioma caatinga do estado de pe-brasil. Rodriguésia 55(84): 101-126.

12. Cabieses F (1993) Apuntes de medicina tradicional. la racionalization de lo irracional. Notes of traditional medicine. Consejo Nacional de Ciencia Technologia Concytec Lima Peru, pp: 414.

13. Webster GL (1957) A monographic study of the west Indian species of Phyllanthus. Journal of the Arnold Arboretum 38: 51-80.

14. Mitra RL, Jain SK (1985) Concept of Phyllanthus (Euphorbiaceae) in Indian floras. Bulletin of the Botanical Survey of India 27(1-4): 161-176.

15. Palaniappan M, Marappa M (2006) RAPD and ISSR analyses reveal low levels of genetic diversity in Phyllanthus amarus. In Proceedings of the $27^{\text {th }}$ International Horticultural Congress-IHC, International Symposium on Plants as Food and Medicine: The Utilization and Development of Horticultural Plants for Human Health, ISHS Acta Horticulture 765.

16. Jain N, Shasany AK, Velusamy S, Subramani, Darokar M, et al. (2003) Molecular diversity in Phyllanthus amarus assessed through RAPD analysis. Current Science 85(10): 1454-1458.

17. Geetha BS, Dabu KK, Seeni S (2003) Genetic variation in south India populations of Phyllanthus amarus Schum. \& Thonn. (Euphorbiaceae) assessed using isozymes. In Proceedings of the $15^{\text {th }}$ Kerala Science Congress, pp: 196-201.

18. Ravikant G, Srirama R, Senthilkumar U, Ganeshaiah KN, Shaanker RU (2011) Genetic resources of Phyllanthus in southern India: identification of geographic and genetic hot spots and its implication for conservation. In: Kuttan R and Harikumar KB (Eds.), Phyllanthus species: scientific evaluation and medicinal applications, Taylor and Francis Group, London, UK, pp: 97-118.

19. Kandavel D, Rani SK, Vinithra MG, Sekar S (2011) Systematic studies in herbaceous Phyllanthus spp. (region: Tiruchirappalli district in India) and a simple key to authenticate 'Bhumyamalaki' complex members. Journal of Phytology 3(2): 37-48.

20. Rout GR, Senapati SK, Aparajita S (2010) Study of relationships among twelve Phyllanthus species with the use of molecular markers. Czech J Genet Plant Breed 3(46): 135-141.

21. Jain N, Shasany AK, Singh S, Khanuja SPS, Kumar S (2008) SCAR markers for correct identification of Phyllanthus amarus, P. fraternus, P. debilis and $P$. urinaria used in scientific investigations and dry leaf bulk herb trade. Planta Med 74(3): 296-301.

22. Bandyopadhyay S, Raychaudhuri SS (2013) Development and comparison of RAPD, SCAR and AFLP markers for distinguishing some medicinally important species of the genus Phyllanthus. Plant Biosystems 147(1): 1-9.

23. Bandyopadhyay S, Raychaudhuri (2010) Development of ITS based SCAR markers for some medicinally important species of Phyllanthus. Asian Journal of Plant Sciences 9(5): 264-270.

24. Theerakulpisut P, Kanawapee N, Maensiri D, Bunnag S, Chantaranothai P (2008) Development of species-specific SCAR markers for identification of three medicinal species of Phyllanthus. Journal of Systematics and Evolution 46(4): 614-621.

25. Srirama R, Senthilkumar U, Sreejayan N, Ravikanth G, Gurumurthy BR, et al. (2010) Assessing species admixtures in raw drug trade of Phyllanthus, a hepato-protective plant using molecular tools. J Ethnopharmacol 130(2): 208-215.

26. Manissorn J, Sukrong S, Ruangrungsi N, Mizukami H (2010) Molecular phylogenetic analysis of Phyllanthus species in Thailand and the application of polymerase chain reaction-restriction fragment length polymorphism for Phyllanthus amarus Identification. Biol Pharm Bull 33(10): 1723-1727.

27. Inglis PW, Mata LR, Silva MJ, Vieira RF, Alves RBN, et al. (2018) DNA barcoding for the identification of Phyllanthus taxa used medicinally in Brazil. Planta Med 84(17): 1300-1310.

28. Senapati SK, Aparajita S, Rout GR (2011) Identification of species-diagnostic inter simple sequence repeat markers for ten Phyllanthus species. Z Naturforsch C (66): 167-172. 
29. Marimuthu J, Antonisamy A (2007) Somoclonal variation studies on Phyllanthus amarus Schum. \& Thonn. Iranian Journal of Biotechnology 5(4): 240-245.

30. Idress M, Irshad M (2014) Molecular markers in plants for analysis of genetic diversity: a review. European Academic Research 2(1): 1513-1540.

31. Costa R, Pereira G, Garrido I, De Sousa MM, Espinosa F (2016) Comparison of RAPD, ISSR, and AFLP molecular markers to reveal and classify orchardgrass (dactylis glomerata L.) germplasm variations. PLoS One 11(4): e0152972.

32. Mosa KA, Gairola S, Jamdade R, El Keblawy A, Shaer KIA, et al. (2019) The promise of molecular and genomic techniques for biodiversity research and DNA barcoding of the Arabian peninsula flora. Front Plant Sci Review 9: 1929.

33. Singh A (2019) Utility of molecular markers in molecular breeding for integrated crop improvement. Bulletin of Environment Pharmacology and Life Sciences 8(2): 1-8.

34. Salim Khan S, Singla RK, Abdin MZ (2011) Assessment of phytochemical diversity in Phyllanthus amarus using HPTLC fingerprints. Indo Global Journal of Pharmaceutical Sciences 1(1): 1-12

35. Nasrulloh R, Rafi M, Wahyuni WT, Shimma S, Heryanto R (2018) HPLC fingerprint and simultaneous quantitative analysis of phyllanthin and hypophyllanthin for identification and authentication of Phyllanthus niruri from related species. Revista Brasileira de Farmacognosia 28(5): 527-532.

36. Buddhachat K, Osathanunkul M, Madesis P, Chomdej S, Ongchai, S (2015) Authenticity analyses of Phyllanthus amarus using barcoding coupled with HRM analysis to control its quality for medicinal plant product. Gene 573(1): 84-90.

37. Maciel MAM, Cunha AF, Kaiser CR, Costa EA, Rocha FF, et al. (2012) Chemical constituents from Phyllanthus amarus Schum. \& Thonn. and its pharmacological effectiveness. In: VK Gupta (Ed.), Medicinal plants: phytochemistry, pharmacology and therapeutics 2(3): 41-52.

38. Ali H, Houghton PJ, Soumyanath A (2006) Alpha amylase inhibitory activity of some Malaysian plants used to treat diabetes; with particular reference to Phyllanthus amarus. J Ethnopharmacol 107(3): 449-455.

39. Abhyankar G, Suprasanna P, Pandey BN, Mishra KP, Rao KV, et al. (2010) Hairy root extract of Phyllanthus amarus induces apoptotic cell death in human breast cancer cells. Innovative Food Science \& Emerging Technologies 11(3): 526-532.

40. Adeneye AA (2012) The leaf and seed aqueous extract of Phyllanthus amarus improves insulin resistance diabetes in experimental animal studies. J Ethnopharmacol 144(3): 705-711.

41. Ajala TO, Igwilo CI, Oreagba IA, Odeku OA (2011) The antiplasmodia effect of the extracts and formulated capsules of Phyllanthus amarus on plasmodium yoelii infection in mice. Asian Pac J Trop Med 4(4): 283287.

42. Ahmad MDS, Bano S, Anwar S (2015) Cancer ameliorating potential of Phyllanthus amarus: In vivo and in vitro studies against aflatoxin B1 toxicity. The Egyptian Journal of Medical Human Genetics 16: 343-353.

43. Appiah-Opong R, Nyarko AK, Dodoo D, Gyang FN, Koram KA, et al. (2011) Antiplasmodial activity of extracts of Tridax procumbens and Phyllanthus amarus in in vitro plasmodium falciparum culture systems. Ghana Med J 4(45): 143-150

44. Belemnaba L, Nitiema M, Ilboudo S, Ouedraogo N, Ouedraogo GG, et al. (2017) Study on antihypertensive activity of an aqueous extract of Anogeissus leiocarpus (AEAL) DC Guill et Perr bark of trunk in LNAME-induced hypertensive rats. Biochemical Pharmacology 139: 105-141.

45. Mohamed SIA, Jantan I, Nafiah MA, Seyed MA, Chan KM (2018) Dendritic cells pulsed with generated tumor cell lysate from Phyllanthus amarus Schum \& Thonn induces anti-tumor immune response. BMC Complement Altern Med (18): 232-244.

46. Eweka AO, Enogieru A (2011) Effects of oral administration of Phyllan- thus amarus leaf extract on the kidneys of adult wistar rats- a histological study. Afr J Tradit Complement Altern Med 3(8): 307-311.

47. Ilangkovan M, Jantan, I, Bukhari SN (2016) Phyllanthin from Phyllanthus amarus inhibits cellular and humoral immune responses in Balb/C mice. Phytomedicine 23 (12): 1441-1450.

48. Ilangkovan M, Jantan I, Mesaik MA, Bukhari SN (2016) Inhibitory Effects of the standardized extract of Phyllanthus amarus on cellular and humoral immune responses in Balb/C Mice. Phytother Res 30(8): 13301338.

49. Kassuya CAL, Silvestre AA, Rehder VLG, Calixto JC (2003) Anti-allodynic and anti-oedematogenic properties of the extract and lignans from Phyllanthus amarus in models of persistent inflammatory and neuropathic pain. Eur J Pharmacol 478(2-3): 145-153.

50. Kiemer AK, Hartung T, Huber C, Vollmar AM (2003) Phyllanthus amarus has anti-inflammatory potential by inhibition of Inos COX-2 and cytokines via the NF-Kappab pathway. J Hepatol 38(3): 289-297.

51. Kushwahaa SK, Dashorab A, Dashoraa N, Patelc JR, Korid ML (2013) Acute oral toxicity studies of the standardized methanolic extract of Phyllanthus amarus Schum \& Thonn. Journal of Pharmacy Research 6: 720-724.

52. Odetola AA, Akojenu SM (2000) Anti-diarrhoeal and gastro-intestinal potentials of the aqueous extract of Phyllanthus amarus (Euphorbiaceae). Afr J Med Med Sci 29(2): 119-122.

53. Ojezele MO, Igbe I, Okhuarobo A (2018) Reproductive indices in malaria infested mice treated with antimalarials, Phyllanthus amarus combined with vitamins. Bulletin of Faculty of Pharmacy 56(2): 179-184.

54. Ojezele MO, Moke EG, Onyesom I (2017) Impact of generic antimalarial or Phyllanthus amarus and vitamin co-administration on antioxidant status of experimental mice infested with Plasmodium berghei. Journal of Basic and Applied Sciences 6(3): 260-265.

55. Poompachee K, Chudapongse N (2012) Comparison of the antioxidant and cytotoxic activities of Phyllanthus virgatus and Phyllanthus amarus Extracts. Med Princ Pract 21(1): 24-29.

56. Putakala M, Gujjala S, Nukala S, Bongu SBR, Chintakunta N, et al. (2017) Cardioprotective effect of Phyllanthus amarus against high fructose diet induced myocardial and aortic stress in rat model. Biomed Pharmacother 95: $1359-1368$

57. Raphael KR, Kuttan R (2003) Inhibition of experimental gastric lesion and inflammation by Phyllanthus amarus extract. J Ethnopharmacol 87(2-3): 193-197.

58. Rajeshkumar NV, Joy KL, Kuttan G, Ramsewak RS, Nair MG, et al. (2002) Antitumour and Anticarnogenic Activity of Phyllanthus amarus extract. J Ethnopharmacol 81(1): 17-22.

59. Raphael RK, Ajith TA, Joseph S, Kuttan R (2002) Anti-mutagenic activity of Phyllanthus amarus Schum. and Thonn. in vitro as well as in vivo. Teratog Carcinog Mutagen 22(4): 285-291.

60. Ravikumar YS, Ray U, Nandhitha M, Perween A, Naika HR, et al. (2011) Inhibition of hepatitis $\mathrm{C}$ virus replication by herbal extract: Phyllanthus amarus as potent natural source. Virus Res 158(1-2): 89-97.

61. Ribeiro AMB, Sousa JN, Costa LM, Oliveira FAA, Santos RC, et al. (2019) Antimicrobial activity of Phyllanthus amarus Schumach. \& Thonn. and inhibition of the Nor A efflux pump of Staphylococcus aureus by Phyllanthin. Microbial Pathogenesis 130: 242-246.

62. Rigueira MG, Giuseppina N, Gomes PFLI, Pires AL, Oliveira KD, et al. (2014) Phyllanthus amarus does not affect hypernociception in experimental autoimmune encephalomyelitis. Planta Med 80(4): 277-282.

63. Taesotikul T, Dumrongsakulchai W, Wattanachai N, Navinpipat V, Somanabandhu A, et al. (2011) Inhibitory effects of Phyllanthus amarus and its Major Lignans on Human Microsomal Cytochrome P450 Activities: Evidence for CYP3A4 Mechanism-Based Inhibition. Drug Metab Pharmacokinet 26(2): 154-161. 
64. Thakur JS, Agarwal RK, Kharya MD (2012) Immobilization mediated enhancement of phyllanthin and hypophyllanthin from Phyllanthus amarus. Chinese Journal of Natural Medicines 3(10): 207-212.

65. Thyagarajan SP, Subramanian S, Thirunalasundari T, Venkateswaran PS, Blumberg BS (1988) Effect of Phyllanthus amarus on chronic carriers of hepatitis B virus. Lancet 2(8614): 764-766.

66. Yuandani JI, Ilangkovan M, Husain K, Chan KM (2016) Inhibitory effects of compounds from Phyllanthus amarus on nitric oxide production, lymphocyte proliferation, and cytokine release from phagocytes. Drug Des Devel Ther (10):1935-1945.

67. Nahar L, Sarker SD, Delazer A (2011) Phytochemistry of the genus Phyllanthus. In Phyllanthus species: scientific evaluation and medicinal applications. In: Kuttan R and Harikumar KB (Eds.), Taylor and Francis Group, CRC Press, Lomdon, UK, pp. 119-138.

68. Maciel MAM, Cunha AF, Dantas TNC, Kaiser CR (2007) NMR Characterization of bioactive Lignans from Phyllanthus amarus Schum \& Thonn. Annals of Magnetic Resonance 6(3): 76-82.

69. Nayak P, Behera PR, Voukkarasu MT, Chand PK (2011) ED-XRF spectrometry-based comparative inorganic profile of leaf-derived in vitro calli and in vivo leaf samples of Phyllanthus amarus Schum. \& Thonn. -A hepatoprotective herb. Appl Radiat Isot 69(3): 567-573.

70. Tripathi AK, Verma RK, Gupta AK, Gupta MM, Khanuja PS (2006) Quantitative determination of phyllanthin and hypo phyllanthin in Phyllanthus species by high-performance this layer chromatography. Phytochem Anal 17(6): 394-397.

71. Shanker K, Singh M, Srivastava V, Verma R, Gupta A, et al. (2011) Simultaneous analysis of six bioactive lignans in Phyllanthus species by reversed phase hyphenated high performance liquid chromatographic technique. Acta Chromatographica 23(2): 321-337.

72. Sharma SK, Arogya SM, Bhaskarmurthy DH, Agarwal A, Velusami CC (2011) Hepatoprotective activity of the Phyllanthus species on tert-butyl hydroperoxide (t-BH)-induced cytotoxicity in HepG2 cells. Pharmacogn Mag 7(27): 229-233.

73. Shatoon S, Rai V, Rawat AKS, Mehrotra S (2006) Comparative pharmacognostic studies of the three Phyllanthus species. J Ethnopharmacol 104(1-2): 79-86.

74. Deepa V, Sridhar R, Goparaju A, Reddy PN, Murthy PB (2012) Nanoemulsified ethanolic extract of Pyllanthus amarus Schum \& Thonn ameliorates CCl4 induced hepatotoxicity in Wistar rats. Indian J Exp Biol 50(11): 785-794.
75. Singh K, Pangha M, Kadyan S, Chaudhary U, Yadav JP (2014) Green silver nanoparticles of Phyllanthus amarus: as an antibacterial agent against multi drug resistant clinical isolates of Pseudomonas aeruginosa. J Nanobiotechnology 12: 40-49.

76. Acharyulu NPS, Dubey RS, Kollu P, Swaminadham V, Kalyani RL, et al. (2014) Green synthesis of cuo nanoparticles using Phyllanthus amarus leaf extract and their antibacterial activity against multidrug resistance bacteria green synthesis of $\mathrm{CuO}$ nanoparticles 3(4): 639-641.

77. Shanti B, Mishra SB, Pandey H, Pande A (2013) Nanosuspension of Phyllanthus amarus extract for improving oral bioavailability and prevention of paracetamol induced hepatotoxicity in Sprague-Dawley rats. Advances in Natural Sciences: nanoscience and nanotechnology 4(035007)

78. Ajitha B, Reddy YAK, Jeon HJ, Ahn CW (2018) Synthesis of silver nanoparticles in an eco-friendly way using Phyllanthus amarus leaf extract: Antimicrobial and catalytic activity. Advanced Powder Technology 29(1): 86-93.

79. Subbaiya R, Lavanya RS, Selvapriya K, Selvam MM (2014) Green synthesis of silver nanoparticles from Phyllanthus amarus and their antibacterial and antioxidant properties. J Nanobiotechnology 3(1): 600-606.

80. Some S, Sen IK, Mandal A, Aslan T, Ustun Y, et al. (2018) Biosynthesis silver nanoparticles and their versatile antimicrobial properties. Materials Research Express 6(1): 012001.

81. Maciel MAM, Anjos GC, Silva DR, Dantas TNC, Felipe MBMC, et al. (2016) Colloidal formulation based on Cocos nucifera L and extract of Phyllanthus amarus Schum. \& Thonn. applied as a green corrosion inhibitor, Patent: Privilege Innovation. Registration number: BR1020160036321. INPI - Instituto Nacional da Propriedade Industrial, Brazil.

82. Padilha DMM, Revoredo SM, Emerenciano DP, Rocha HAO, Figueiredo JR, et al. (2017) Formulated antioxidant and antimicrobial with controlled release of the bioactive principles of Phyllanthus amarus Schum. \& Thonn. applied as follicular culture medium, Patent: Privilege Innovation. Registration number: BR1020170122867. INPI - Instituto Nacional de Propriedade Intelectual, Brazil.

For possible submissions Click below: 